\title{
Ultrasound assessment of visual loss during severe preeclampsia: a case report
}

\author{
Fehmi Ferhi ${ }^{1,2,3 *}$ (D) Abdeljalil Khlifi, ${ }^{3,4}$, Feten Hachani ${ }^{3,4}$, Khalil Tarmiz ${ }^{1,2,3}$ and Khaled Benjazia ${ }^{1,2,3}$
}

\begin{abstract}
Bilateral retinal detachments and cortical blindness are rare complications of preeclampsia and the association of the two pathologies is exceptional. We report the case of a preeclamptic patient who presented with an acute bilateral vision loss. Besides, her ocular ultrasound revealed bilateral retinal detachments and an elevated optic nerve sheath diameter. The patient underwent an urgent cesarean section. Subsequently, magnetic resonance imaging and ocular fundus examination confirmed the diagnosis.
\end{abstract}

Keywords: Cortical blindness, Ocular ultrasound, Optic nerve sheath diameter, Preeclampsia, Retinal detachments

\section{Background}

Preeclampsia is a multisystem hypertensive disorder and is mainly responsible for the world's largest maternal morbidity and mortality. Visual symptoms, such as scotomota, amaurosis, blurred vision, diplopia, chromatopsia, or homonymous hemianopsia, may occur in $25 \%$ of preeclamptic women [1]. Blindness is usually attributed to retinal abnormalities including edema and vascular changes, such as retinal arteriolar vasospasm, thrombosis of the central retinal artery, or retinal detachment. Transient cortical blindness due to focal cerebral edema is estimated to occur in about $1-15 \%$ of eclamptic women [2].

Given the magnitude of the neurological effects of preeclampsia, real-time assessment of the cerebrovascular and ocular changes associated with this condition are challenging with established modalities such as computed tomography, magnetic resonance imaging and ocular fundus examination $[3,4]$.

We report the case of a preeclamptic patient who presented with acute bilateral vision loss. Bedside ocular ultrasound revealed a bilateral retinal detachment and an elevated optic nerve sheath diameter.

*Correspondence: fehmiferhi@hotmail.fr

1 Department of Anaesthesiology and Critical Care Medicine, Farhat

Hached University Hospital Center, 4002 Sousse, Tunisia

Full list of author information is available at the end of the article

\section{Case report}

A 24-year-old primigravida woman presented to the obstetric emergency department at 35 weeks of gestation complaining of bilateral vision loss. There was nothing abnormal with her previous medical history and she had no history of previous ophthalmologic disorders. The patient reported a mild headache that has been going on for the past 2 days.

Clinical examination showed an important peripheral edema. Vital signs were as follows: pulse rate 105 beats/ min, blood pressure $186 / 115 \mathrm{mmHg}$, respiratory rate 20 breaths/min, temperature $36.9{ }^{\circ} \mathrm{C}$, and oxygen saturation $98 \%$ on air. Visual acuity in the two eyes was fingercounting at less than $1 \mathrm{~m}$. Her pupils were equal and reactive to light. Neurologic examination showed exaggerated deep tendon reflexes.

Proteinuria dipstick was $3+$. Laboratory tests revealed anemia at $103 \mathrm{~g} / \mathrm{L}$, thrombocytopenia with platelets count at $97 \times 10^{9} / \mathrm{L}$ and elevated liver enzymes (GOT $82 \mathrm{U} / \mathrm{I}, \mathrm{GPT} 78 \mathrm{U} / \mathrm{I}$, alkaline phosphatase $168 \mathrm{U} / \mathrm{I})$. The remaining laboratory tests, including electrolytes, creatinine, bilirubin, and coagulation tests, were within normal limits.

A bedside ultrasound was performed by an anesthesiologist trained in bedside focused ultrasonography using a $7.5-\mathrm{MHz}$ linear probe (mindray DC 70 Shenzhen, China). Sagittal and transverse planes of the right and left globe were obtained by asking the patient to close her eyelids and then applying ultrasound gel to the inside 
and outside of a sterile sheath covering the probe as it was gently placed on each eyelid. To measure the optic nerve sheath diameter (ONSD), the placement of the probe was adjusted to view the entry of the optic nerve into the globe. We used an electronic caliper and an axis perpendicular to the optic nerve $3 \mathrm{~mm}$ behind the lamina cribosa. The Mechanical Index and Thermal Index were reduced to 0.2 and 1 , respectively.

Sonographies detected in the right and left eye a hyper-echoic stripe extending to the optic nerve head, but not across it. The point of fixation of the retina at the optic nerve head was respected. When the patient was also asked to look in various directions with her eyelids closed, the hyper-echoic line undulated with the associated ocular movements, which was suggestive of retinal detachment (RD). The ONSD was measured at $6.9 \mathrm{~mm}$ in the right eye (Fig. 1a) and $6.6 \mathrm{~mm}$ in the left eye (Fig. 1b), suggesting an elevated intracranial pressure. The patient tolerated the sonogram without pain or complications.

Obstetric ultrasound revealed an intra-uterine fetus with a heart rate of 140 beats/min and a fetal biometry consistent with a 34-week gestation.

Based on these findings, the patient was diagnosed with severe preeclampsia complicated by hemolysis, elevated liver enzymes and low platelets (HELLP) syndrome, bilateral RD and cerebral edema. Therefore, the patient underwent an urgent cesarean section delivery under spinal anesthesia and was immediately administrated an intravenous Magnesium Sulfate and Nicardipine infusion which were maintained $24 \mathrm{~h}$ after delivery. Blood pressure was then controlled with Methyldopa 500 mg 6 hourly and Amlodipine $10 \mathrm{mg} 12$ hourly.

Magnetic resonance imaging (MRI) performed $24 \mathrm{~h}$ after delivery showed T2 hyperintensities on flair indicating parieto-occipital and temporal distribution of vasogenic edema. A dilated fundoscopic examination using an ophthalmoscope performed by an ophthalmologist subsequently confirmed the diagnosis of bilateral exudative retinal detachments.

During 1 week, a daily ocular sonogram was performed. The ONSD was back to a normal range after arterial blood pressure control. The RD regressed but it was difficult to objectify it.

Within 3 weeks of delivery, her visual acuity had returned to normal without any further treatment. At that time, the slit lamp examination was normal.

\section{Discussion}

This case highlights a possible association between two etiologies of vision loss during severe preeclampsia and the interest of bedside ocular sonography for reliable assessing.

The most frequent ophthalmologic manifestation of preeclampsia is the vasoconstriction of the retinal arterioles. The prevalence of this disorder increases with severity [5]. It is mostly asymptomatic and regresses without sequelae after delivery. Other clinically noisier manifestations are very rare, and we can mention among them cortical blindness and retinal serous detachment. The association of the two pathologies is exceptional [6].

Computed tomography (CT) and MRI brain imaging are mandatory to make the diagnosis of cerebral edema, but they are expensive and cannot be carried out in realtime assessing [3]. Retinal examination for papilledema or RD seems sometimes difficult. Actually most anesthesiologists and emergency physicians are more comfortable using an ultrasound machine than an ophthalmoscope. In addition, ultrasound is bedside available, reproducible and non-invasive [4].
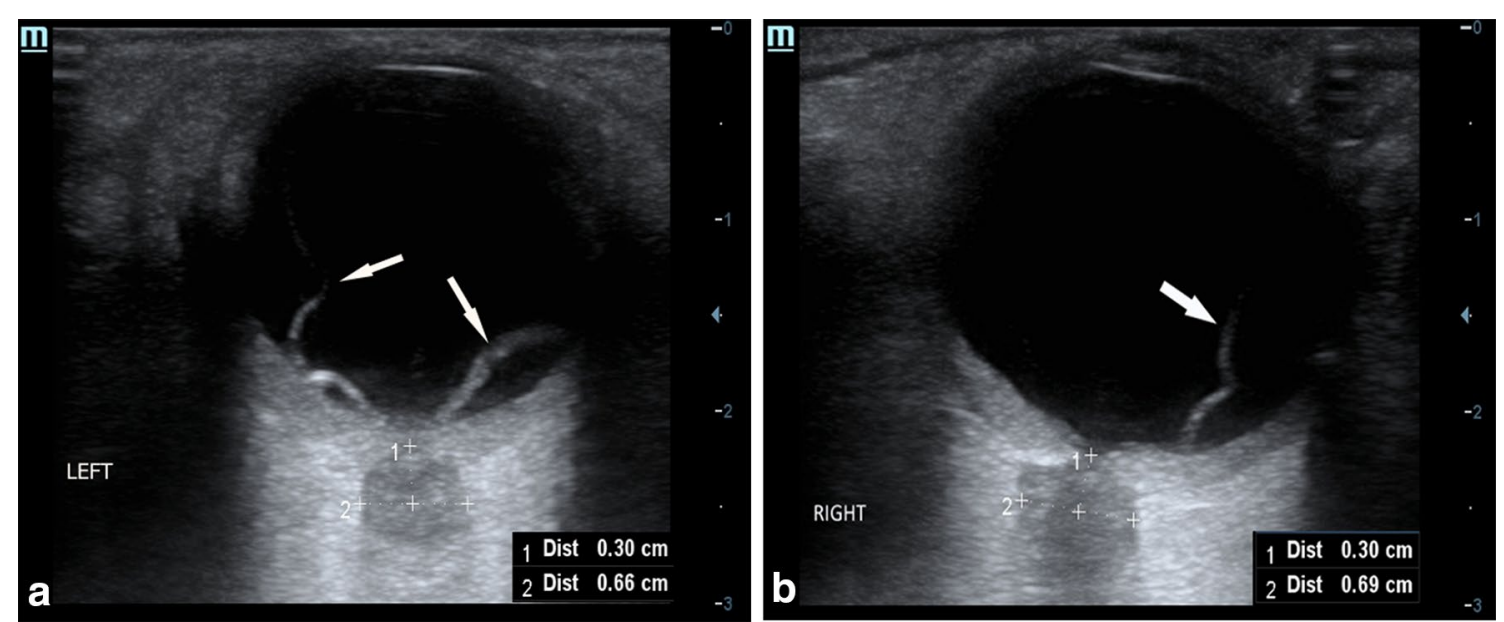

Fig. 1 a Ocular ultrasound of the left eye demonstrating retinal detachment (white arrows) and optic nerve sheath diameter enlargement. b Ocular ultrasound of the right eye demonstrating retinal detachment (white arrow) and optic nerve sheath diameter enlargement 
Preeclampsia can be associated with brain edema and raised intracranial pressure (ICP) [6]. Increases in ICP are transmitted by the cerebrospinal fluid down the perineural subarachnoid space of the optic nerve, causing an expansion of the nerve sheath [7]. ONSD measured by ultrasound has proved to be highly predictive of intracranial pressure in the settings of traumatic brain injury and neurological pathology [8]. Dubost et al. [9] measured ONSD in patients with preeclampsia and compared the findings with those obtained in healthy pregnant women. They found that median ONSD values were significantly higher in preeclamptic patients at delivery and that in about $20 \%$ of preeclamptic patients ONSD values were above $5.8 \mathrm{~mm}$. This threshold diameter was associated with $95 \%$ risk of raised ICP (above $20 \mathrm{mmHg}$ ) [8]. This technique is rapidly acquired by non-radiologist physicians $[10,11]$.

$\mathrm{RD}$ is a well-documented complication of preeclampsia affecting $0.1-2 \%$ of patients [12]. Women who have HELLP syndrome are 7 times more likely to develop RD than those who do not have HELLP syndrome. RD is more frequent in primiparous women. It is usually bilateral and tends to be diagnosed during the last trimester or shortly after delivery [13]. The main pathogenesis of this disease includes generalized vasoconstriction and choroidal ischemia affecting the retinal pigment epithelium, leading to a breakdown of the blood-retinal barrier and a leakage of proteins and fluid from the choriocapillaries into the subretinal space [14]. Focal ischemia caused by capillary obstruction is even more severe when associated to hemolysis of the red blood cells, such as the case of HELLP syndrome [13]. Patients usually have complete recovery of vision with complete resolution of RD within 2-12 weeks postpartum [14].

Ocular ultrasound has proved to be a useful tool for diagnosing most ophthalmic pathologies including retinal detachments, vitreous hemorrhage, papilledema, lens dislocation and globe rupture. The sensitivity and specificity of ultrasound for the diagnosis of retinal detachments were reported to be high [15].

Regarding the mechanical and biological risks of exposing the eye to high-frequency probes, sonography side effects have not been reported up to now. In animal studies, rabbit corneas and retinas were exposed to ultrasound ranging from 10 to $60 \mathrm{MHz}$ for up to $30 \mathrm{~min}$ with no deleterious effects [16]. Nevertheless, mechanical energy is transmitted into the eye and more than $4-10 \times 10^{6}$ oscillations may warm the intraocular fluid. Therefore, it is important to limit the examination time and gain according to the ALARA ("as low as reasonably applicable") principle and reduce Mechanical Index and Thermal Index less than 0.23 and 1, respectively.
Actually preeclampsia especially when severe is associated with an increased risk of maternal retinal disease in the decades following pregnancy [17]. Ocular ultrasound may have a useful role in the assessment strategy of neurological and retinal events in preeclampsia, potentially allowing for more appropriately targeted therapy and survey [3].

In this case, ocular ultrasound was performed by an anesthesiologist using a $7.5-\mathrm{MHz}$ linear probe placed gently over the closed eyelid. This rapid bedside examination quickly helped us to refine our diagnosis in a preeclamptic patient with a life-threatening condition and allowed us to make a rapid decision.

\section{Abbreviations}

RD: retinal detachments; ONSD: the optic nerve sheath diameter; HELLP syndrome: hemolysis, elevated liver enzymes, and low platelets syndrome; MRI: magnetic resonance imaging; CT: computed tomography; ICP: intracranial pressure.

\section{Authors' contributions}

FF realized POCUS, AK and FH helped in case-report redaction, KT and KB revised the manuscript. All authors read and approved the final manuscript.

\section{Author details}

1 Department of Anaesthesiology and Critical Care Medicine, Farhat Hached University Hospital Center, 4002 Sousse, Tunisia. ${ }^{2}$ The Research Unit on Maternal Morbidity and Mortality UR17SP08, Sousse, Tunisia. ${ }^{3}$ Ibn Jazzar Medical School Sousse, Avenue Mohamed El Karoui, 4002 Sousse, Tunisia. ${ }^{4}$ Department of Obstetrics and Gynaecology, Farhat Hached University Hospital Center, 4002 Sousse, Tunisia.

\section{Acknowledgements}

None.

Competing interests

The authors declare that they have no competing interests.

Availability of data and materials

This manuscript adhered to institutional policies regarding ultrasonography image collection and research.

\section{Consent for publication}

We obtained all the necessary approval and consent from the patient to use the information and pictures for both research and publication.

Ethics approval and consent to participate

This case was performed in accordance with the Declaration of Helsinki and was approved by the local ethics committee.

Funding

This study was not supported financially.

\section{Publisher's Note}

Springer Nature remains neutral with regard to jurisdictional claims in published maps and institutional affiliations.

Received: 29 August 2017 Accepted: 27 January 2018

Published online: 12 February 2018 


\section{References}

1. Roos NM, Wiegman MJ, Jansonius NM, Zeeman GG (2012) Visual disturbances in (pre)eclampsia. Obstet Gynecol Surv 67(4):242-250. https://doi. org/10.1097/ogx.0b013e318250a457

2. Cunningham FG, Fernandez CO, Hernandez C (1995) Blindness associated with preeclampsia and eclampsia. Am J Obstet Gynecol 172:1291-1298. https://doi.org/10.1016/0002-9378(95)91495-1

3. Kane SC, Brennecke SP, Da Silva Costa F (2017) Ophthalmic artery doppler analysis: a window into the cerebrovasculature of women with preeclampsia. Ultrasound Obstet Gynecol 49(1):15-21. https://doi.org/10.1002/ uog.17209

4. Rollins M, Flood P (2012) Imaging intracranial pressure: an introduction to ultrasonography of the optic nerve sheath. Anesthesiology 116:983-984. https://doi.org/10.1097/aln.0b013e31824c16e4

5. Jaffe G, Schatz H (1987) Ocular manifestations of preeclampsia. Am J Ophthalmol 103(3 Pt 1):309-315

6. Zeeman GG (2009) Neurologic complications of pre-eclampsia. Semin Perinatol 33(3):166-172. https://doi.org/10.1053/j.semperi.2009.02.003

7. Hansen H, Helmke K (1996) The subarachnoid space surrounding the optic nerves. An ultrasound study of the optic nerve sheath. Surg Radio Anat 18(4):323-328. https://doi.org/10.1007/BF01627611

8. Dubourg J, Javouhey E, Geeraerts T, Messerer M, Kassai B (2011) Ultrasonography of optic nerve sheath diameter for detection of raised intracranial pressure: a systematic review and meta-analysis. Intensive Care Med 37(7):1059-1068. https://doi.org/10.1007/ s00134-011-2224-2

9. Dubost C, Le Gouez A, Jouffroy V, Roger-Christoph S, Benhamou D, Mercier FJ, Geeraerts T (2012) Optic nerve sheath diameter used as ultrasonographic assessment of the incidence of raised intracranial pressure in preeclampsia: a pilot study. Anesthesiology 116:1066-1071. https://doi. org/10.1097/aln.0b013e318246ea1a
10. Potgieter DW, Kippin A, Ngu F, McKean C (2011) Can accurate ultrasonographic measurement of the optic nerve sheath diameter (a non-invasive measure of intracranial pressure) be taught to novice operators in a single training session? Anaesth Intensive Care 39:95-100

11. Lochner P, Coppo L, Cantello R, Nardone R, Naldi A, Leone MA, Brigo F (2016) Intra- and interobserver reliability of transorbital sonographic assessment of the optic nerve sheath diameter and optic nerve diameter in healthy adults. J Ultrasound 19(1):41-45. https://doi.org/10.1007/ s40477-014-0144-z

12. Schultz KL, Birnbaum AD, Goldstein DA (2005) Ocular disease in pregnancy. Curr Opin Ophthalmol 16(5):308-314. https://doi.org/10.1097/01. icu.0000179803.42218.cc

13. Vigil-De Gracia P, Ortega-Paz L (2011) Retinal detachment in association with pre eclampsia, eclampsia and HELLP syndrome. Int J Gynecol Obstet 114:223-225. https://doi.org/10.1016/j.ijgo.2011.04.003

14. Amer R, Nalcı H, Yalçındăg N (2017) Exudative retinal detachment. Surv Ophthalmol 62(6):723-769. https://doi.org/10.1016/j. survophthal.2017.05.001

15. Vrablik ME, Snead GR, Minnigan HJ, Kirschner JM, Emmett TW, Seupaul RA (2015) The diagnostic accuracy of bedside ocular ultrasonography for the diagnosis of retinal detachment: a systematic review and meta-analysis. Ann Emerg Med 65(2):199-203. https://doi.org/10.1016/j. annemergmed.2014.02.020

16. Torloni MR, Vedmedovska N, Merialdi M, Betrán AP, Allen T, ISUOG-WHO Fetal Growth Study Group et al (2009) Safety of ultrasonography in pregnancy: WHO systematic review of the literature and meta-analysis. Ultrasound Obstet Gynecol 33:599-608. https://doi.org/10.1002/uog.6328

17. Auger N, Fraser WD, Paradis G, Healy-Profitós J, Hsieh A, Rhéaume MA (2017) Preeclampsia and long-term risk of maternal retinal disorders. Obstet Gynecol 129(1):42-49. https://doi.org/10.1097/ aog.0000000000001758

\section{Submit your manuscript to a SpringerOpen ${ }^{\circ}$ journal and benefit from:}

- Convenient online submission

- Rigorous peer review

- Open access: articles freely available online

- High visibility within the field

- Retaining the copyright to your article

Submit your next manuscript at $\boldsymbol{\nabla}$ springeropen.com 